\title{
Novel Anti-Alzheimer's Dimer Bis(7)-Cognitin: Cellular and Molecular Mechanisms of Neuroprotection Through Multiple Targets
}

\author{
Wenming Li,* Marvin Mak, ${ }^{*}$ Hualiang Jiang, ${ }^{\dagger}$ Qinwen Wang, ${ }^{\ddagger}$ Yuanping Pang, ${ }^{\S}$ Kaixian Chen, ${ }^{\dagger}$ \\ and Yifan Han* \\ *Department of Applied Biology \& Chemical Technology, Institute of Modern Chinese Medicine, the Hong Kong Polytechnic \\ University, Hong Kong SAR, China, ${ }^{\dagger}$ Center for Drug Discovery and Design, State Key Laboratory of Drug Research, Shanghai \\ Institute of Materia Media, Shanghai 201203, China, ${ }^{\ddagger}$ Department of Physiology, Medical School, Ningbo University, Ningbo \\ 315211, China, and ${ }^{\S}$ Mayo Foundation for Medical Education and Research, Rochester, MN 55905
}

\begin{abstract}
Summary: Alzheimer's disease (AD) is a progressive and degenerative brain disorder that has emerged as one of the major public health problems in adults. Unfortunately, its molecular pathology and therapeutic strategies remain elusive. Because there are multiple factors closely indicated in the pathogenesis of $\mathrm{AD}$, multiple drug therapy will be required to address the varied pathological aspects of this disease. Existing pharmacological approaches with one-molecule-one-target are limited in their ability to modify the pathology of AD. Novel therapeutics strategies comprise multifunctional compounds specifically designed to target concurrently on different sites at multifactorial etiopathogenesis of $\mathrm{AD}$, thereby providing greater therapeutic efficacy. Over the past decade, our group
\end{abstract}

has developed several series of dimeric acetylcholinesterase (AChE) inhibitors derived from tacrine and huperzine A, a unique anti-Alzheimer's drug originally discovered from a traditional Chinese medicinal plant. Bis(7)-Cognitin, one of our novel dimers, through inhibition of AChE, N-methyl-D-aspartate receptor, nitric oxide synthase, and amyloid precursor protein/ $\beta$-amyloid cascade concurrently, possesses remarkable neuroprotective activities. More importantly, the synergism between these targets might serve as one of the most effective therapeutic strategies to arrest/modify pathological process of $\mathrm{AD}$ in addition to improving the cognitive functions for $\mathrm{AD}$. Key Words: Bis(7)-Cognitin, multiple targets, neuroprotection, AChE, NMDA receptor.

\section{INTRODUCTION}

Alzheimer's disease (AD) is a chronic neurodegenerative disease that attacks the brain and results in impaired memory, thinking, and behavior in the elderly. ${ }^{1}$ It has become the fourth leading cause of death in developed nations following heart disease, cancer, and stroke. However, only in the U.S., the costs related to AD exceed those related to cancer and heart disease. Most AD sufferers are over 65 years old, and the incidence rate for people over age 85 years approaches $50 \% .^{1,2}$ The disease is estimated to affect approximately 4.5 million people in the U.S. alone. ${ }^{3}$ Due to cultural factors, it is quite likely that, at present, $\mathrm{AD}$ is underdiagnosed in many countries.

Address correspondence and reprint requests to: Yifan Han, Ph.D., Department of Applied Biology \& Chemical Technology, Institute of Modern Chinese Medicine, the Hong Kong Polytechnic University, Hong Kong SAR, China. E-mail: bcyfhan @ polyu.edu.hk.
But as the world population continues to age, a more accurate picture of the extent of the disease should emerge. Therefore, development of an effective therapy will have tremendous value from scientific and economic standpoints. ${ }^{4}$

The main symptomatic characteristics of AD are memory impairment, loss of decision- making ability and judgment. The major neuropathological features of AD are amyloid plaques and neurofibrillary tangles with the loss of neurons in the brain. To date the exact causes of $\mathrm{AD}$ are still unknown and no effective therapy for $\mathrm{AD}$ is available. ${ }^{4,5}$ However, increasing neurochemical and pharmacological evidence has linked $\mathrm{AD}$ to the cholinergic and glutamatergic deficiency. Several approaches exist in theory, but the use of the acetylcholinesterase (AChE) inhibition approach, which is in regard to the enhancement of the function of central cholinergic neurons by permitting acetylcholine to remain in the synaptic cleft longer through inhibiting the 
<smiles></smiles><smiles>COc1cc2c(cc1OC)C(=O)C(CC1CCN(Cc3ccccc3)CC1)C2</smiles>

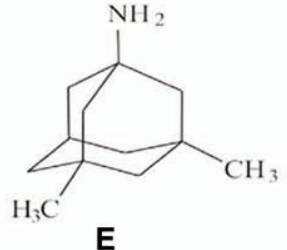

C<smiles>CCN(C)C(=O)Oc1cccc(C(C)N(C)C)c1</smiles>
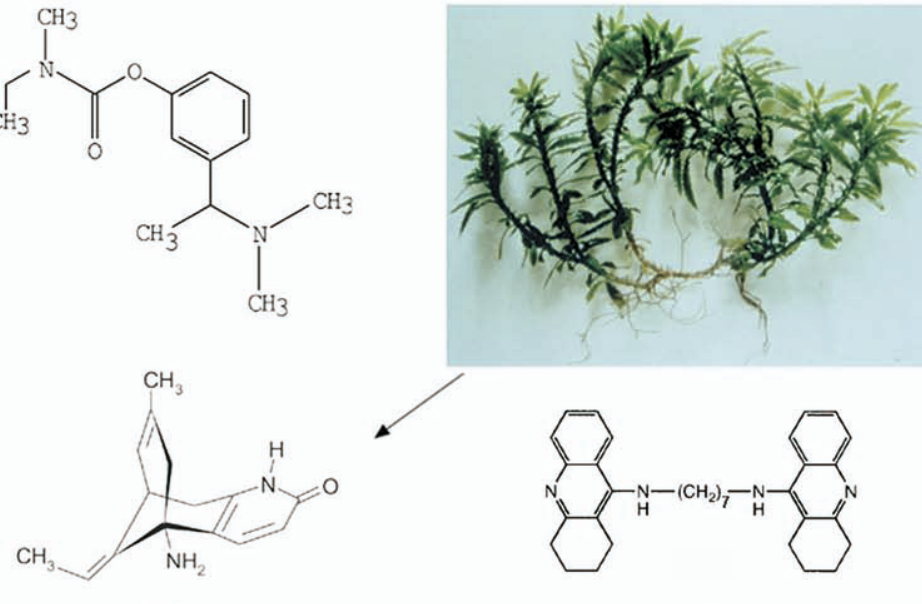

$\mathbf{F}$

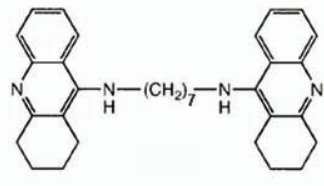

G

FIG. 1. The structures of currently-used drugs for the treatment of AD: (A) tacrine; (B) donepezil (E2020); (C) rivastigmine; (D) galantamine; (E) memantine; $(F)$ Huperzine A (HA) (extracted from Chinese Herb Huperzia Serrata [i.e., Qing Ceng Ta, color panel]) and (G) bis(7)-Cognitin.

enzyme with inhibitors, has produced the most encouraging results in clinical practice. So far, the four such AChE inhibitors (FIG. 1A-D), tacrine (Cognex [Pfizer and Warner-Lambert, New York, NY], 1993), donepezil (also known as E2020, Aricept [Pfizer, New York, NY], 1996), rivastigmine (Exelon [Novartis Pharmaceuticals, Basel, Switzerland], 2000), and galanthamine (Reminyl [Johnson \& Johnson and Shire Pharmaceuticals, London, UK], 2001), have demonstrated efficacy, and have been approved by the U.S. Food and Drug Administration for the treatment of AD. ${ }^{6}$ Huperzine A (HA; FIG. 1F), originally discovered from the traditional Chinese medicine Huperzia serrata (also known as Qian Ceng Ta; color panel of FIG. 1), represents one highly promising agent. ${ }^{7-10} \mathrm{HA}$, a novel Lycopodium alkaloid chemically unique from other agents under study for treating the AD patients, is a reversible and mixed competitive AChE inhibitor. Its selectivity, potency, and duration of $\mathrm{AChE}$ inhibition rival those of physostigmine, galanthamine, and tacrine. ${ }^{11}$ Furthermore, HA has been found to be an effective memory enhancer in a number of different animal models. Preliminary clinical trials have also demonstrated that HA induced significant improvement of memory deficiencies in the elderly and $\mathrm{AD}$ patients, while at the same time being devoid of any notable side effects. ${ }^{12,13}$ Memantine (Namenda [Forest Pharmaceuticals Inc., New York, NY]; FIG. 1E), a moderate antagonist of the N-methyl-D-aspartate (NMDA) receptor, reduces glutamate-induced excitocytotoxicity in vivo and in vitro and prevents neurodegeneration in $\mathrm{AD}$ patients. Therefore, this drug, which was approved in October 2003 by the U.S. Food and Drug Administration for treating AD, seems to be a new hope for treating moderate-to-severe $\mathrm{AD}$ patients. $^{14}$

In general, AChE inhibitors have limited success as they only improve memory in mild dementia, but cannot stop the process of neurodegeneration. The magnitude of response to $\mathrm{AChE}$ inhibitors depends on the integrity of presynaptic neurons. ${ }^{14}$ Obviously, effectiveness of these agents will decrease with increasing severity of AD. Tacrine is rarely prescribed nowadays due to serious side effects, including hepatotoxicity. Galanthamine, rivastigmine, and donepezil are most effective when treatment is begun in the early stages of $\mathrm{AD}^{6,15}$ but show the gastrointestinal side effects (peripheral cholinergic effects). The use of HA as a therapeutic for AD has been inhibited in the U.S., as well as other countries, because of problems of intellectual property protection (absence of a patent) and high cost (the natural resource is rare). All of these AChE inhibitors have been shown to only modestly slow the progression of cognitive symptoms and reduce problematic behavior in some people. Furthermore, half of those who have taken these drugs showed no response. ${ }^{6,15}$ Although memantine has been approved for treatment of moderate to severe $\mathrm{AD}$, its clinical efficacy seems to be less than that of the AChE inhibitors. It is increasingly being used as an adjuvant to cholinesterase inhibitor therapy, and studies indicate that targeting both the cholinergic and glutamate pathway could result in better clinical outcomes. ${ }^{15}$

Since multi-factorial etiopathogenesis is closely indicated in AD, as well as in other neurodegenerative disorders, $\mathrm{AD}$ will require multiple drug therapy to address the varied pathological aspects. ${ }^{16}$ Multiple drug strategies have been successfully used in traditional medicine (in China and in many other countries) for thousands of years, including the current drug cocktail to suppress the spreading of human immunodeficiency virus (HIV). ${ }^{17}$ Even if the strategy of combining drugs with different therapeutic targets is workable, the development of multi-functional compounds will obviate the challenge 
of administering multiple, single-drug entities with potentially different degrees of bioavailability, pharmacokinetics, and metabolism. The simplification of the therapeutic regimen for $\mathrm{AD}$ patients who have difficulty with compliance is extremely important. ${ }^{16}$ The concept of synergistic actions of multiple-functions from a singlemolecule drug has been realized in the use of Sutent with inhibition of various kinases for successfully curing several kinds of cancers. ${ }^{18}$ Therefore, the new potential approaches pioneered by Youdim ${ }^{16,19}$ have been developed expressly to target multiple sites in the brain with single molecular entities for the treatment of memory and cognition impairment; and single drugs developed with a network approach target two or more of the following factors synergistically for cognitive enhancements: AChE, $\beta$-amyloid ( $\mathrm{A} \beta$ ), tau protein, monoamine oxidase, metal ions, reactive oxygen species (ROS), and neuroprotection. Encouragingly, well-controlled trials of memantine/donepezil dual therapy have shown superior efficacy in moderate to severe AD patient subgroups. ${ }^{20}$ Consequently, there has been a major rush among neuroscience research institutions and pharmaceutical firms worldwide to search for safer and more effective multifunctional therapeutic agents for AD. Over the past decade, enormous efforts from our group have been directed toward the development of drugs that are more effective and potent than the current AChE inhibitors. To date, three novel series of tacrine/HA analogs have been developed by linking tacrine, or the fragment of HA to itself, or the fragment of HA to tacrine. ${ }^{21,22}$ These dimeric drugs are much easier to produce and have been shown to be more potent than either tacrine or HA alone, and represent a combination of the best of the Western and Chinese palliative drugs for AD. In this review, we demonstrate that the novel promising anti-Alzheimer's candidate bis(7)-tacrine (FIG. 1), one of our novel dimers, possesses multi-potencies including anti-AChE, anti-NMDA receptors and anti-nitric oxide synthase (NOS) signaling, the regulation of the downstream signal of NMDA receptors, and the reduction of $A \beta$ neurotoxicity for synergistically combating AD.

\section{DESIGN, SYNTHESIS AND EVALUATION OF NOVEL ANTI-ACHE DIMERS}

AChE has an ellipsoidal shape with dimensions $\sim 45 \AA \times 60 \AA \times 65 \AA$. It consists of a 12-stranded, central mixed $\beta$-sheet surrounded by $14 \alpha$ helices. The first and last pairs of strands each form $\beta$-hairpin loops that are only loosely hydrogen-bonded to the eight central, super-helically twisted strands. ${ }^{23}$ The active site of AChE consists of two subsites: 1) the "esteratic" site and 2) the "anionic" site. These two sites are believed to be responsible for the catalytic machinery and the choline-binding pocket of the enzyme, respectively. By sequence comparison and site-di- rected mutagenesis, $\mathrm{Ser}^{200}$, $\mathrm{His}^{440}$ and $\mathrm{Glu}^{327}$ are found to be the three residues in the active site forming a planar array that resembles the catalytic triad of chymotrypsin and other serine proteases. ${ }^{23}$ In addition to the catalytic site, $\mathrm{AChE}$ possesses another subsite that is able to bind acetylcholine or other quaternary ligands. Using photo-labe $\mathrm{l}^{24}$ and affinity label, ${ }^{25}$ residues 251 to 264 and residues 270 to 278 in peptide sequences have been identified as part of the peripheral binding sequences. These two peptides lie on the surface of the protein near the rim of the enzyme gorge and bind the bis-quaternary ligands, which usually serve as inhibitors, at one end to the peripheral binding peptide and the other end to the deeper end or the aromatic lining of the enzyme pocket. Because this subsite is distinct from the other two catalytic subsites, it is therefore named the "peripheral" site. ${ }^{23}$ By using a fluorescent probe, this peripheral site can be shown to be acting as an uncompetitive inhibitor binding site. ${ }^{26}$ The two catalytic sites, together with the third peripheral site, make up the active site gorge of the enzyme (FIG. 2). The peripheral site provides aromatic guidance by setting an array of low-affinity binding sites to the ligands. This site involves three conserved aromatic residues: $\operatorname{Tyr}^{70}$, $\operatorname{Trp}^{279}$, and $\mathrm{Tyr}^{121}$, which increase the concentration of acetylcholine at the opening of the active site gorge, facilitating passage through the narrower portion of the gorge toward the catalytic site. ${ }^{23}$ Once the ligands are trapped at the top of the enzyme gorge, they can easily diffuse into the active site deep in the gorge. ${ }^{23,27}$ Structurally, this enzyme gorge is a deep and narrow channel extending from the surface to halfway inside of the enzyme ( $\sim 20 \AA$ long). The gorge is so deep and broad that it can bind many different substrates, agonists, and inhibitors. ${ }^{23}$ To facilitate rational drug design for AChE inhibitors based on the hypothesis of dual binding, an automated computer docking system was used to devise synthesis of tacrine analogs with superior therapeutic potential. ${ }^{28}$ This system can estimate the potential energetically favorable binding sites in the AChE active site gorge by rotating the incoming substrate-tacrine and match each available conformation of these two counterparts. On the other hand, with this docking system, the existence of the peripheral site near the opening of the enzyme gorge was further confirmed. This is reasonable, because strong binding at the peripheral site may hinder the entering of the substrate into the lower portion of the enzyme gorge, which in turn lowers the efficacy of hydrolysis. Through structural modification of tacrine, a dimeric tacrine analog linked by an alkylene chain (so named bis(n)-Cognitin) offers a much stronger potency and selectivity towards AChE, where bis(n)Cognitin with an appropriate chain length linker (such as heptylene) simultaneously binds at both the catalytic and the peripheral sites (FIG. 3). Since the peripheral site is absent in butyrylcholinesterase (BuChE), this dimeric 


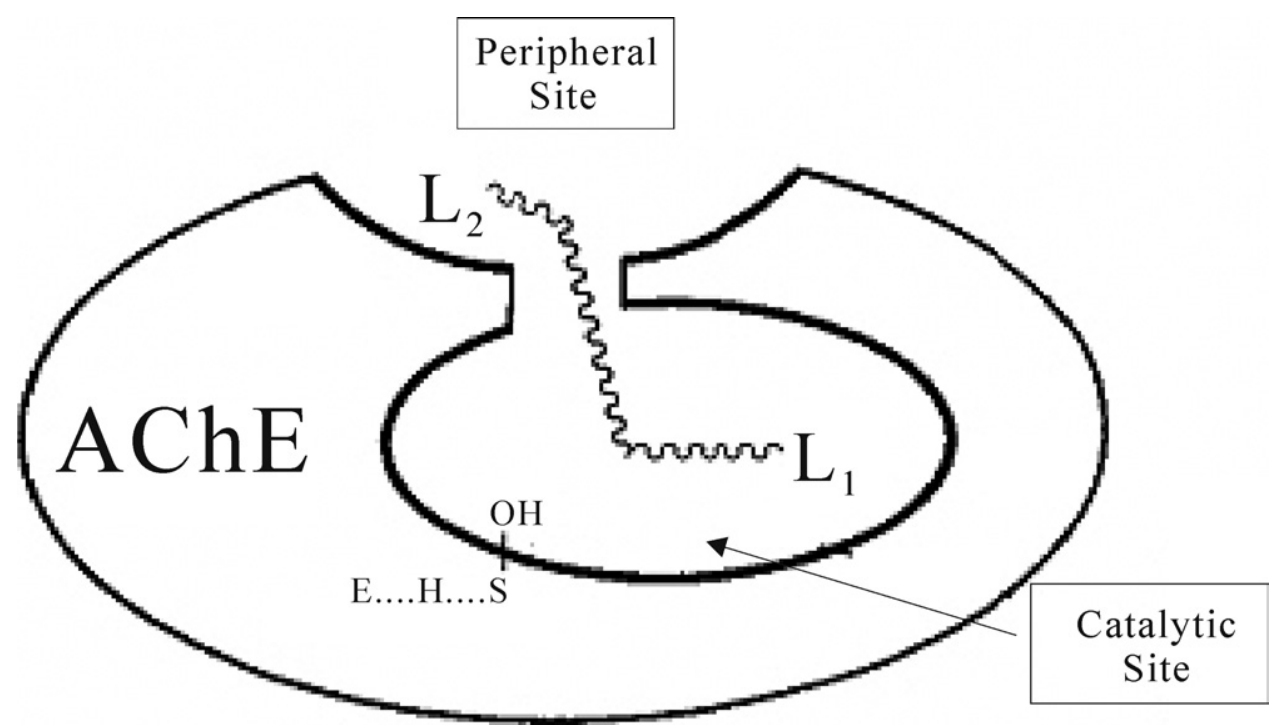

FIG. 2. A diagrammatic illustration of dual-site binding of a dimeric inhibitor $L_{1}-L_{2}$ to the catalytic and peripheral sites of acetylcholinesterase (AChE). Key residues involved in substrate turnover and inhibitor binding are marked. Torpedo AChE numbering is used.

analog provides a better selectivity toward AChE over BuChE in terms of its binding property. ${ }^{28}$

Applying the above strategy to tacrine, we have obtained alkylene linked bis(n)-Cognitin analogs. ${ }^{28}$ Effective alkylene-bridged analogs require chains of the correct length (number of methylene units) coupled to the parent structure at the appropriate point. By computational calculations, nine methylene units were the approximate chain length. Newly synthesized compounds were tested in vitro for selectivity and potency as enzyme inhibitors. Rat serum and extracts from rat brain were used, respectively, as sources of BuChE and AChE for this screening work. As compared with tacrine, bis(7)Cognitin (1,7- $N$-heptylene-bis-9,9' -amino-1,2,3,4-tetra- hydroacridine) proved 1,000 times more potent and 10,000 times more selective in inhibiting rat brain $\mathrm{AChE}$, and inhibitory potency within the series of compounds was related to the length of the alkylene chain (FIG. 4). The best chain length determined by experiment was reached in the compound with seven methylene groups between tacrine residues.

Would this remarkable in vitro potency enhancement displayed by bis(7)-Cognitin translate to enhanced potency in reversing cognitive deficits in animal models? Was it possible to prove that the dramatic potency enhancement enjoyed by bis(7)-Cognitin was due to simultaneous binding of the tacrine units to the catalytic and peripheral sites of AChE? The anti-cho-

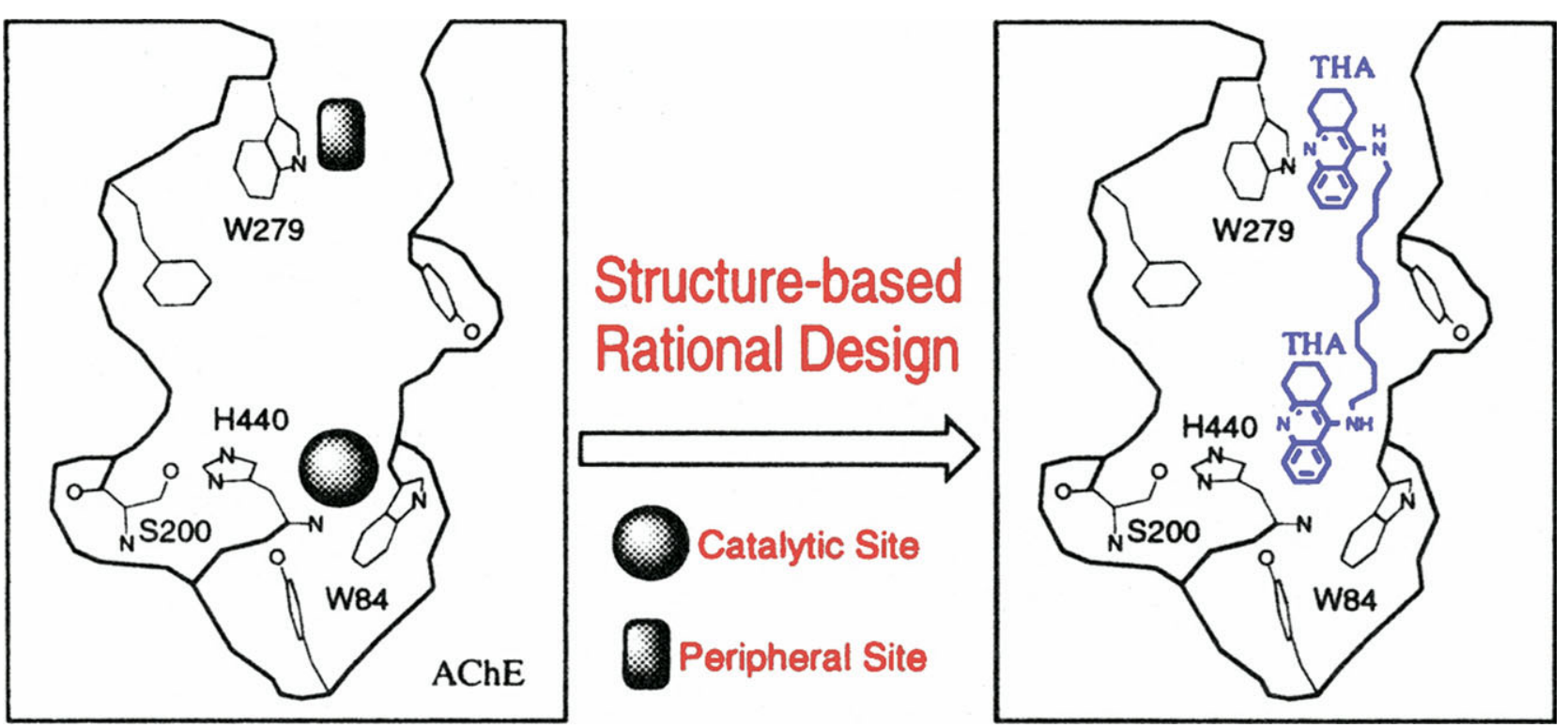

FIG. 3. Structure-based rational drug design for novel dimeric acetylcholinesterase (AChE) inhibitor: the diagram shows the fitting of dimeric tacrine analog into the enzyme gorge by binding to both the catalytic and peripheral sites (adapted from Pang et al., ${ }^{28} 1996$ ). THA $=$ tacrine. 


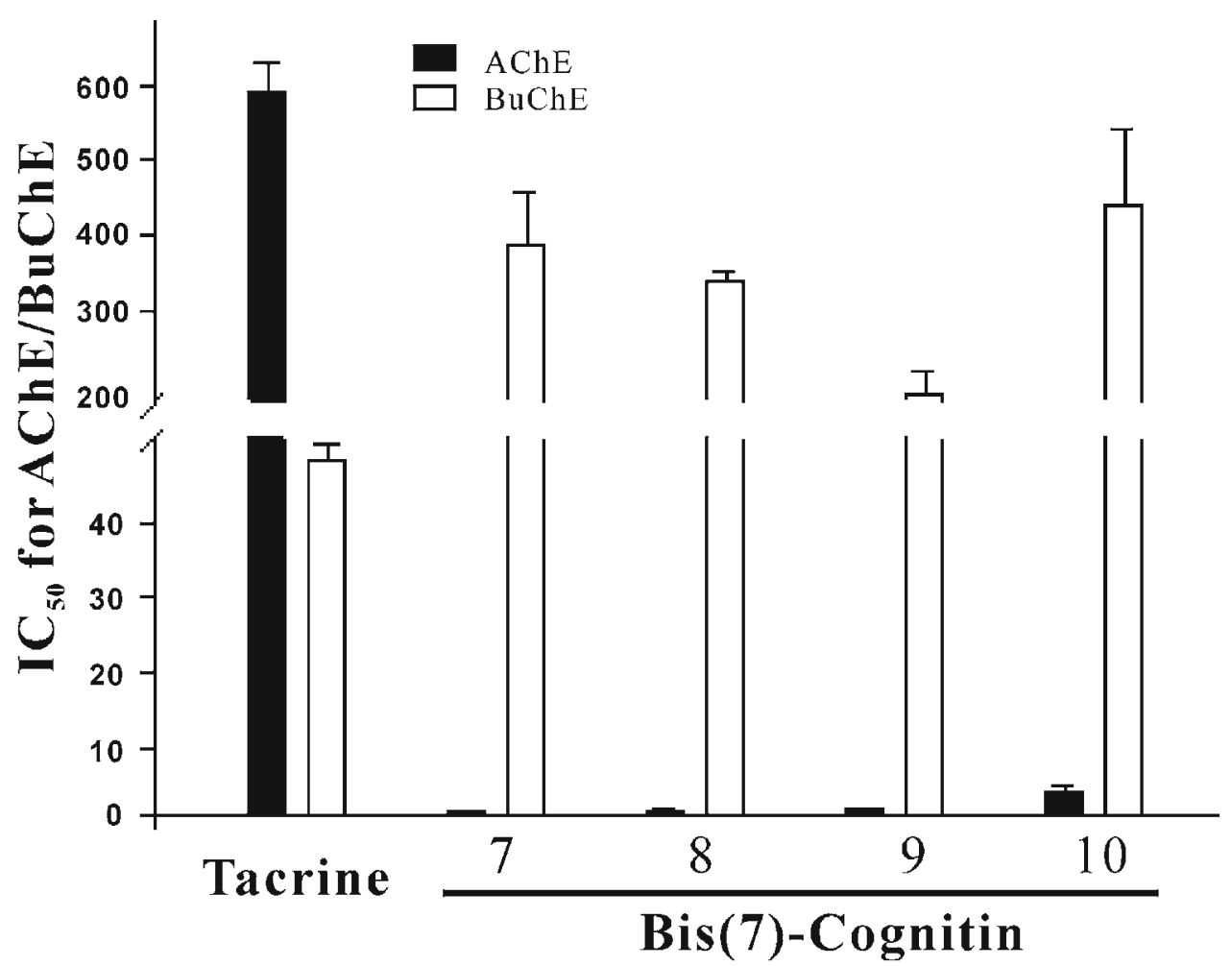

FIG. 4. Inhibition of acetylcholinesterase (AChE) and butyrylcholinesterase (BuChE) by tacrine and its dimeric analogs (plotted based on the data from Pang et al., ${ }^{28}$ 1996).

linesterase (ChE) activities of the novel dimers were evaluated in vitro and in vivo using a spectrophotometric method ${ }^{29}$ with minor modifications. It has been shown that the $50 \%$ inhibitory concentration $\left(\mathrm{IC}_{50}\right)$ on AChE by bis(7)-Cognitin was estimated to be $1.6 \mathrm{nM}$ in a reversible manner, which was more potent than that induced by other known AChE inhibitors. Although bis(7)-Cognitin inhibits BuChE with a lower $\mathrm{IC}_{50}$, it has been shown that this chemical has the highest selectivity for AChE. Furthermore, the kinetic analysis of bis(7)-Cognitin indicated that inhibition pattern was of mixed competitive type with an apparent $\mathrm{K}_{\mathrm{i}}$ value of $1.4 \sim 2.8 \mathrm{nM}$. Significant inhibition of AChE activity has also been demonstrated in various brain regions (cortex, hippocampus, striatum) of rats following the administration of bis(7)-Cognitin. It has also been shown that bis(7)- Cognitin demonstrated higher potency and selectivity than tacrine towards AChE inhibition in vivo. Furthermore, it has been found that after oral or peritoneal injection administration, bis(7)-Cognitin exhibits higher efficacy and AChE/BuChE selectivity than tacrine (FIG. 5). According to the time course of ChE activity determined from 15 to 360 min after single intragastric injection administration, bis(7)-Cognitin, similar to tacrine, reversibly inhibits AChE in both cortex and whole brain, or inhibits $\mathrm{BuChE}$ in serum. ${ }^{30}$

\section{Multifunctional potencies of bis(7)-Cognitin}

Pharmacological studies of bis(7)-Cognitin are still in progress, but at this point the results are extremely promising (Table 1). Enhancement of learning and memory function may improve the life quality of $\mathrm{AD}$ patients. Many possible approaches have been investigated in developing AD therapeutic drugs for promoting cognitive function, but to date only the cholinergic and glutamatergic therapies seem to be most effective. The novel dimeric AChE inhibitor bis(7)Cognitin demonstrates potent $\mathrm{AChE}$ inhibition in vitro and in vivo; therefore, we hypothesized that these dimers may enhance the learning and memory functions of AD patients. Several contemporary learningmemory models were used to determine whether this dimer can improve the memory impairments caused by some neurotoxins. The relative potency of bis(7)-Cognitin to shorten the escape latency in Morris water maze was 24 or 12 times greater than that of tacrine after oral or peritoneal injection administration of scopolamine, respectively. ${ }^{31}$ In addition, bis(7)-Cognitin $(0.18 \sim 0.51 \mu \mathrm{mol} / \mathrm{kg})$, tacrine $(2.56 \mu \mathrm{mol} / \mathrm{kg})$, and donepezil $(0.72 \mu \mathrm{mol} / \mathrm{kg})$ reversed both working and reference memory impairments of rats induced by scopolamine in partially baited radial arm maze. Similar memory enhancement has been demonstrated in rats by using open eight-arm radial maze with treatment 

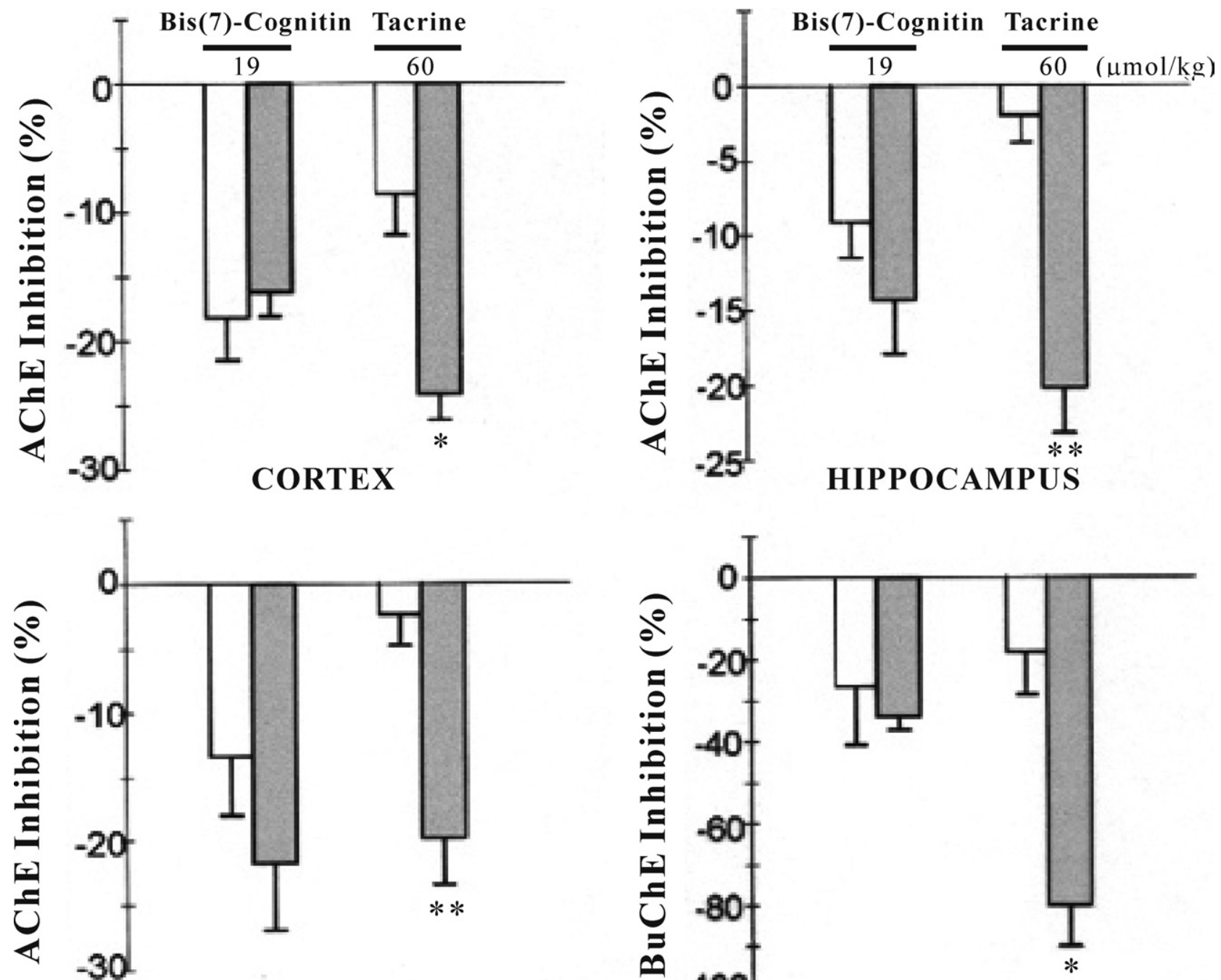

STRIATUM

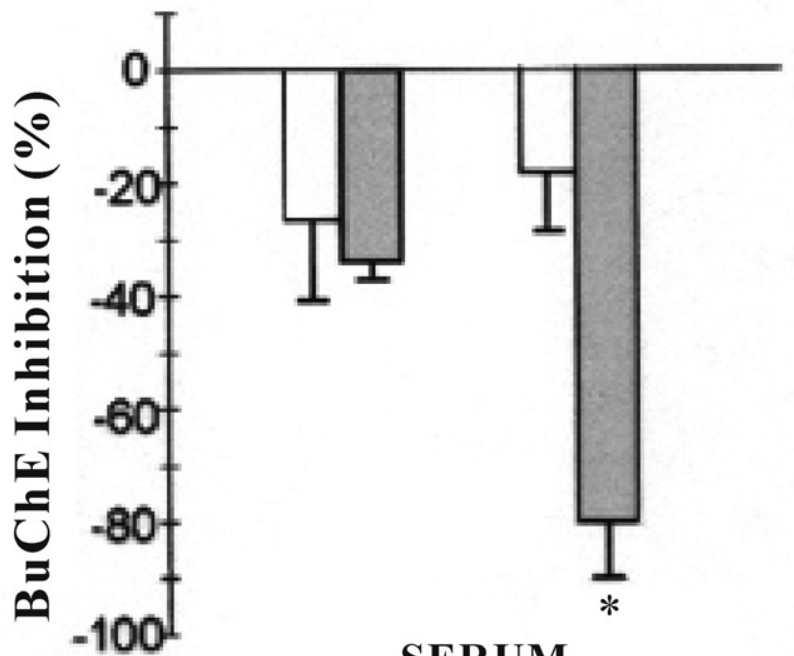

SERUM

\section{$\square$ p.o. $\square$ i.p.}

FIG. 5. Anticholinesterase activities of bis(7)-Cognitin in rats; ${ }^{*}<0.05$ and ${ }^{*}<0.01$ versus p.o. group with the same drug at the same dosage. $\mathrm{AChE}=$ acetylcholinesterase; p.o. $=$ per os; i.p. = peritoneal injection.

with bis(7)-Cognitin $(0.18 \sim 0.51 \mu \mathrm{mol} / \mathrm{kg})$, tacrine $(2.56 \mu \mathrm{mol} / \mathrm{kg})$, and donepezil $(0.72 \mu \mathrm{mol} / \mathrm{kg})$. Furthermore, oral administration of bis(7)-Cognitin $(0.22 \sim 0.89 \mu \mathrm{mol} / \mathrm{kg})$ dose-dependently reversed the AF64A-induced latency delay in Morris water maze to the level of the saline control group. ${ }^{32}$

The precise mechanisms implicated in the pathogenesis of $\mathrm{AD}$ have not yet been fully elucidated; however, the neuronal loss via neuronal apoptosis, caused by various neurotoxins (e.g., glutamate and $\beta$-amyloid protein), seems to be the most fundamental reason underlying this disease. ${ }^{14,33}$ Because apoptosis may be reversed only within a limited period of time, compounds that prevent apoptosis may have a therapeutic significance for $\mathrm{AD} .{ }^{34}$ Based on its special structure, bis(7)-Cognitin may possess multiple neuroprotective properties, which tacrine or other AChE inhib- itors do not, or only weakly, possess. To date, it has been found that bis(7)-Cognitin can prevent neurotoxicity induced by several stimuli in vitro and in vivo. In the in vitro study, bis(7)-Cognitin protects astrocytes from ischemiainduced cell injury in primary cultured mouse astrocytes, indicating that the drug may be beneficial for the treatment of vascular dementia. ${ }^{35}$ Pretreatment of cells with bis(7)Cognitin or tacrine attenuated hydrogen peroxide $\left(\mathrm{H}_{2} \mathrm{O}_{2}\right)$ induced cell toxicity in pheochromocytoma (PC12) cells, and bis(7)-Cognitin demonstrated higher potency than tacrine in improving redox desequilibrium. ${ }^{36}$ Recently, we have also found that bis(7)-Cognitin prevents glutamate-induced apoptosis in cerebellar granule neurons (CGNs) $)^{22,37}$ and attenuates $\beta$-amyloid-induced neuronal apoptosis in rat cortical neurons, ${ }^{38}$ and it reverses the inhibition of long-term potentiation (LTP) by $\mathrm{A} \beta$ in hippocampal slices. In the in 
Table 1. Summary of In Vitro and In Vivo Studies of bis(7)-Cognitin

\begin{tabular}{|c|c|c|}
\hline Assay & $\begin{array}{l}\text { bis(7)- } \\
\text { Cognitin }\end{array}$ & $\begin{array}{l}\text { Ratio bis(7)- } \\
\text { Cognitin/tacrine }\end{array}$ \\
\hline In vitro $\mathrm{AChE} \mathrm{IC}_{50} *$ & $1.5 \mathrm{nM}$ & 149 \\
\hline $\begin{array}{l}\text { In vitro } \mathrm{AChE} \\
\text { selectivity*,†}\end{array}$ & 99 & 250 \\
\hline $\begin{array}{l}\text { In vivo } \mathrm{AChE} \\
\text { inhibition } \\
\text { potency* }\end{array}$ & NA & 10 \\
\hline $\begin{array}{l}\text { Effective dose, water } \\
\text { maze (p.o.) }\end{array}$ & $0.35 \mu \mathrm{mol} / \mathrm{kg}$ & 24 \\
\hline $\mathrm{LD}_{50}$ (p.o.) & $325 \mu \mathrm{mol} / \mathrm{kg}$ & 0.5 \\
\hline Therapeutic index & 930 & 47 \\
\hline $\begin{array}{l}\mathrm{GABA}_{\mathrm{A}} \text { antagonism } \\
\mathrm{IC}_{50} \text { (patch-clamp) }\end{array}$ & $5.6 \mu \mathrm{M}$ & 18 \\
\hline NMDA receptors & $0.66 \mu \mathrm{M}$ & 83 \\
\hline
\end{tabular}

$\mathrm{GABA}=$ gamma-aminobutyric acid; $\mathrm{NA}=$ data not available; p.o. $=$ per os.

*In rat cortex.

${ }^{\top} \mathrm{AChE}$ selectivity is defined as 50\% inhibitory concentration $\left(\mathrm{IC}_{50}\right)$ ratios of $\mathrm{AChE}$ and $\mathrm{BuChE}$.

${ }^{\ddagger}$ In rat.

vivo study, bis(7)-Cognitin reverses the occlusion of bilateral common carotid arteries-induced injuries in brain and latency delay in Morris water maze, and reduces the infarction size and neurological scoring caused by middle cerebral arty occlusion in rats. ${ }^{39}$ The molecular mechanisms underlying multiple neuroprotective activities of bis(7)Cognitin will be presented in the following sections.

\section{Prevention of excitotoxicity by bis(7)-Cognitin via the concurrent blockade of NMDA receptors and NOS}

The excessive activation of the NMDA receptor/nitric oxide (NO) pathway has been proposed to be involved in the neuropathology of $\mathrm{AD}$, as well as other various neurodegenerative disorders. ${ }^{22,40}$ The neuroprotective properties of bis(7)-Cognitin on glutamate-induced excitotoxicity were investigated in primary cultured CGNs. ${ }^{37}$ Exposure of CGNs to $75 \mu \mathrm{M}$ glutamate resulted in neuronal apoptosis as demonstrated by Hoechst staining, TUNEL (FIG. 6A), and DNA fragmentation assays. The bis(7)-Cognitin treatment (0.01-1 $\mu \mathrm{M})$ to CGNs remarkedly reduced glutamate-induced apoptosis in concentration- and time-dependent manners. However, donepezil and other AChE inhibitors, even at concentrations where they inhibited $\mathrm{AChE}$ to the similar extent as $1 \mu \mathrm{M}$ bis(7)-Cognitin failed to prevent glutamateinduced excitotoxicity in CGNs; moreover, both atropine and dihydro- $\beta$-erythroidine, the cholinoreceptor antagonists, did not affect the anti-apoptotic properties of bis(7)Cognitin, suggesting that the neuroprotection of bis(7)Cognitin appears independent of inhibiting $\mathrm{AChE}$ and cholinergic transmission. In addition, extracellular regulated kinase $1 / 2$ and p38 pathways, downstream signals of NMDA receptors, were rapidly activated after the exposure of glutamate to CGNs. Bis(7)-Cognitin inhibited the apoptosis and the activation of these two signals with the same efficacy as the co-application of PD98059 and SB203580. Furthermore, using fluorescence $\mathrm{Ca}^{2+}$ imaging, patch-clamp and receptor-ligand binding techniques bis(7)-Cognitin was found to effectively buffer the intracellular $\mathrm{Ca}^{2+}$ increase triggered by glutamate, to reduce NMDA-activated currents, and to compete with $\left[{ }^{3} \mathrm{H}\right] \mathrm{MK}-801$ with $\mathrm{IC}_{50}$ of $0.763 \mu \mathrm{M}$ in rat cerebellar cortex membranes (FIGS. 6B and 6C).

However, it has further been found that although bis(7)-Cognitin has a similar affinity and potency to memantine in blocking NMDAR, this dimer is much more potent than memantine in preventing glutamate-induced excitotoxicity in neurons. ${ }^{14,37}$ Therefore, in addition to its blockade of NMDA receptors, the mechanisms of bis(7)-Cognitin against glutamate-induced excitoxicity were further probed. First, we demonstrated that NO mediated glutamate-induced excitotoxicity in primary cultured neurons. ${ }^{22}$ Compared with the NOS inhibitor, $\mathrm{N}^{\mathrm{G}}$-monomethyl- L-arginine (L-NMMA), and the NMDA receptor antagonist memantine, bis(7)-Cognitin was found to be more potent in reducing NO-mediated excitotoxicity and the release of NO caused by glutamate (FIG. 7A). Moreover, under different treatment durations, such as LNMMA, but not like MK-801 and memantine, bis(7)-Cognitin showed time-dependent potencies in both neuroprotection, and the reduction of the release of NO against glutamate. The neuroprotective effects were significant even when added $1 \mathrm{~h}$ after the glutamate challenge (FIG. 7B). Bis(7)-Cognitin was also found to be as moderately potent as memantine in competing with $\left[{ }^{3} \mathrm{H}\right] \mathrm{MK}-801$, inhibiting NMDA-evoked currents and reducing glutamatetriggered calcium influx, which eventually reduced neuronal NOS activity. More importantly, at neuroprotective concentrations, bis(7)-Cognitin substantially reversed the overactivation of neuronal NOS caused by glutamate without interfering with the basal activity of NOS. Furthermore, in vitro pattern analysis demonstrated that bis(7)-Cognitin competitively inhibited both purified neuronal and inducible NOS with $\mathrm{IC}_{50}$ at 2.9 and $9.3 \mu \mathrm{M}$, but not endothelial NOS (Table 2). This result was further supported by molecular docking simulations that showed hydrophobic interactions between bis(7)-Cognitin and neuronal NOS isozyme (FIG. 7C). Collectively, these results strongly suggest that the substantial neuroprotection against glutamate by bis(7)-Cognitin might be mediated synergistically through the moderate blockade of NMDA receptor and selective inhibition of neuronal NOS (FIG. 7D).

\section{Intracellular mechanisms of bis(7)-Cognitin against glutamate-induced excitotoxicity in primary cultured neurons}

In spite of its similar affinity and potency to memantine in blocking NMDA receptors, bis(7)-Cognitin is much 
A
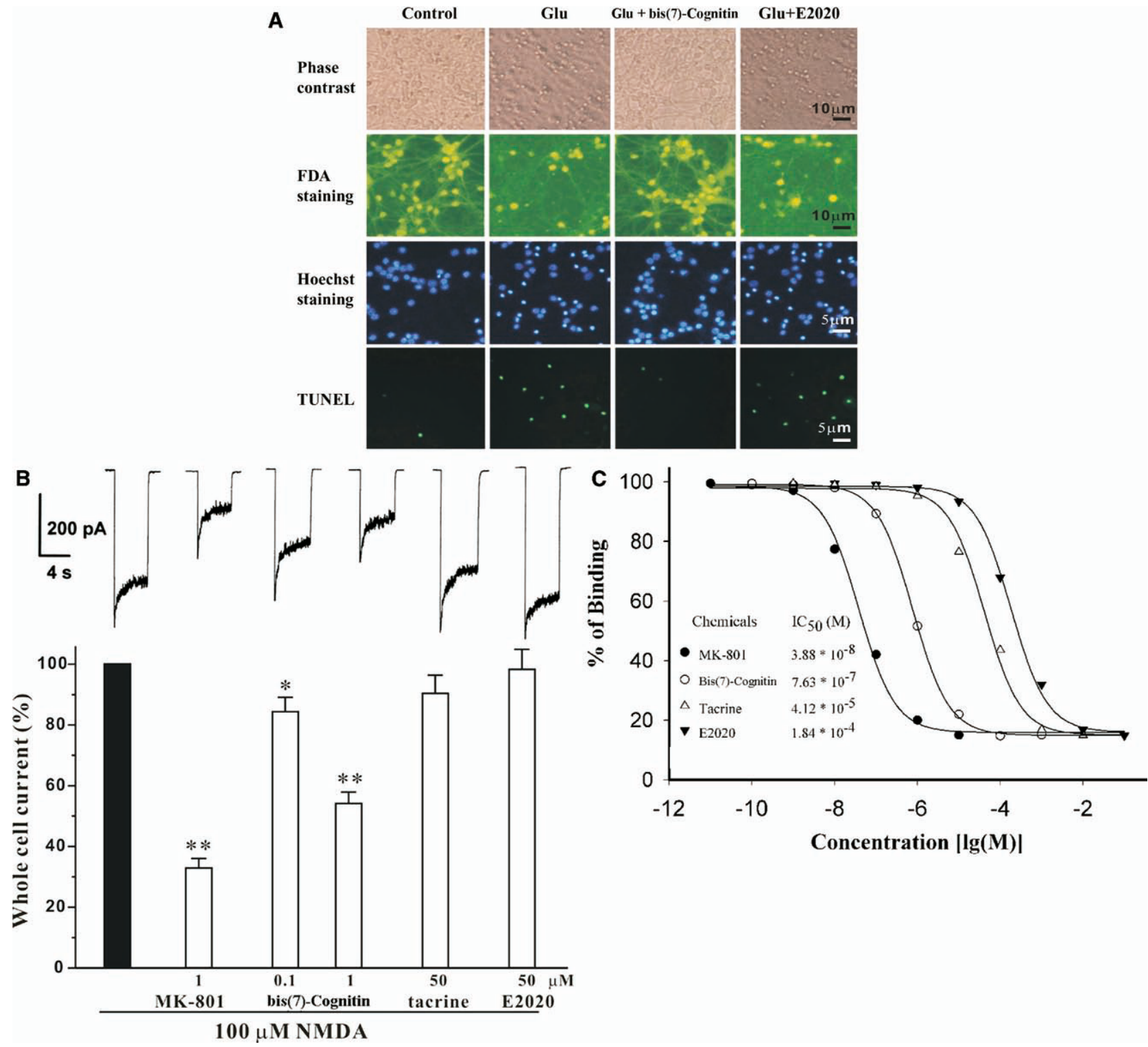

FIG. 6. Bis(7)-Cognitin prevents the glutamate-induced apoptosis in CGNs by the blockade of N-methyl-D-aspartate (NMDA) receptors. A: bis(7)-Cognitin blocks the hallmarks of apoptosis induced by glutamate in cerebellar granule neurons (CGNs), at 8 days in vitro, CGNs were preincubated with or without $1 \mu \mathrm{M}$ bis(7)-Cognitin or $50 \mu \mathrm{M}$ donepezil (E2020) and exposed to $75 \mu \mathrm{M}$ glutamate (Glu) $2 \mathrm{~h}$ later. At $24 \mathrm{~h}$ after glutamate challenge, CGNs were assayed with a phase contrast microscope, fluorescein diacetate staining, Hoechst 33324 staining, or terminal transferase dUTP nick end labeling assay. B: bis(7)-Cognitin inhibits NMDA-evoked whole cell current in primary cultured hippocampal neurons. Upper panel, representative whole cell recordings with bars indicating the times at which N-methyl-D-aspartate (NMDA) $(100 \mu \mathrm{M})$ alone, or NMDA with MK-801 $(1 \mu \mathrm{M})$, bis(7)-Cognitin $(0.1$ or $1 \mu \mathrm{M})$, tacrine $(50 \mu \mathrm{M})$, and E2020 $(50 \mu \mathrm{M})$ were primed in the same patch clamped cell in the presence of $10 \mu \mathrm{M}$ glycine. Lower panel, the effects of bis(7)-Cognitin on the NMDA-evoked whole cell current responses. C: Inhibition of $\left.{ }^{3} \mathrm{H}\right] \mathrm{MK}-801$ binding to rat cerebellar cortex membranes by bis(7)Cognitin. The membranes from rat cerebellar cortex were incubated with $\left[{ }^{3} \mathrm{H}\right] \mathrm{MK}-801(4 \mathrm{nM})$ and the chemicals indicated at gradually increasing concentrations. The graphs were plotted by Sigmaplot software (adapted from Li et al., ${ }^{37} 2005$ ).

more potent than memantine in preventing glutamate-induced excitotoxicity in CGNs, and our data has shown that bis(7)-Cognitin, but not memantine, added at 1 hour after glutamate challenge, can significantly reduce the cell death induced by glutamate in CGNs (FIG. 7B), ${ }^{22}$ indicating that this chemical may have some intracellular targets against the excitotoxicity. Furthermore, we have found that posttreatment with bis(7)-Cognitin, but not memantine, can block the declines of mitochondrial membrane potential and
ATP production, two important indexes for mitochondrial dysfunction, induced by glutamate (FIGS. 8A and 8B). Taken together, these results suggest that maintaining mitochondrial functions may be the mechanisms underlying the post-treatment with bis(7)-Cognitin against glutamateinduced excitotoxicity.

Increasing evidence supports that the mitochondrial dysfunction, mainly caused by abnormal changes of mitochondrial proteins, plays a pivotal role in gluta- 

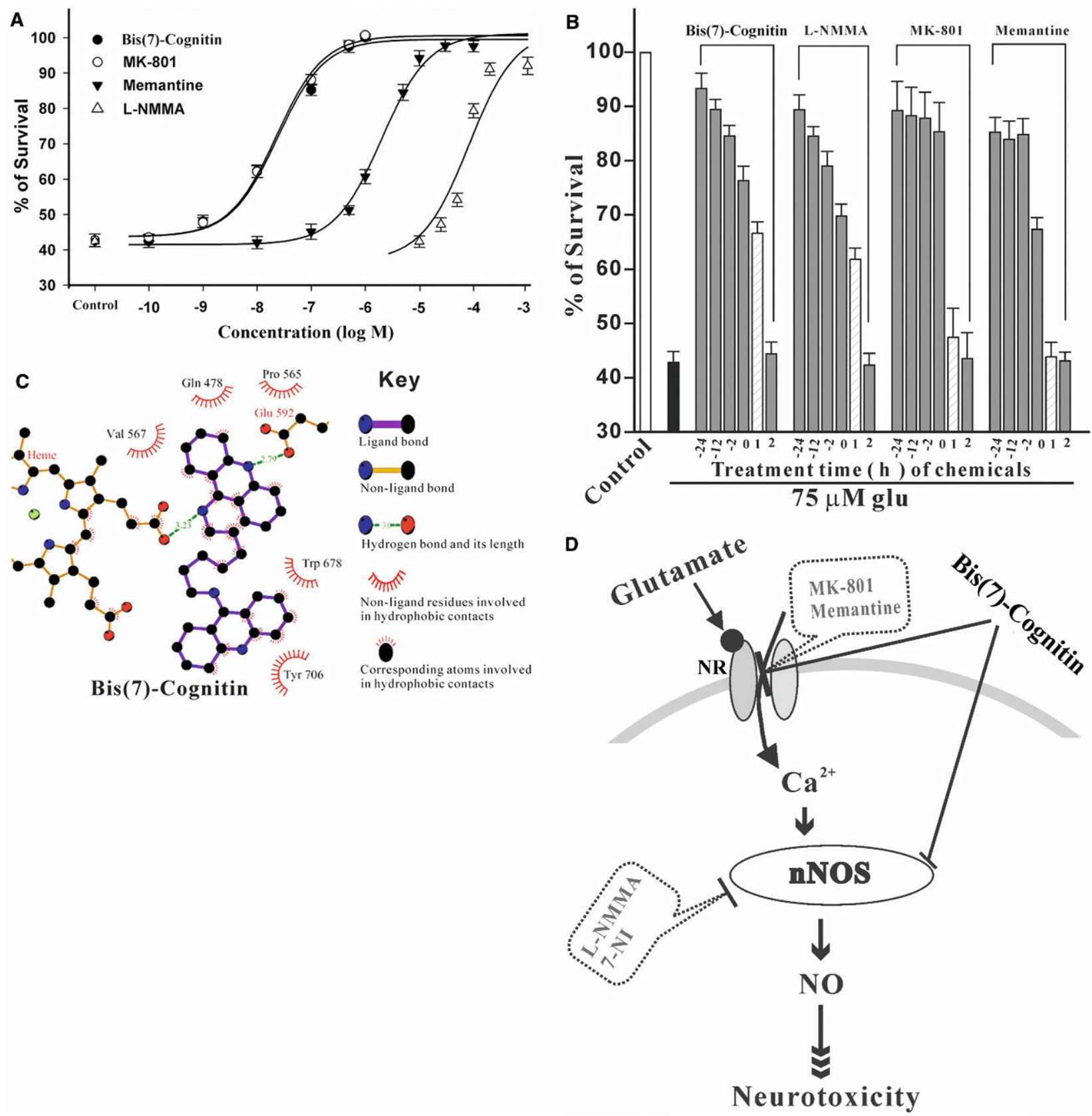

FIG. 7. Synergistic neuroprotection by bis(7)-Cognitin via concurrent blockade of N-methyl-D-aspartate (NMDA) receptors and NOS. $\mathrm{A}$ : bis(7)-Cognitin prevents glutamate-induced excitotoxicity more potently than do memantine and $\mathrm{N}^{\mathrm{G}}$-monomethyl- $\mathrm{L}$-arginine (LNMMA). At 8 days in vitro, cerebellar granule neurons (CGNs) were pretreated with bis(7)-Cognitin (0.1 nM to $1 \mu M) / \mathrm{MK}-801$ (0.1 nM to $1 \mu \mathrm{M}) /$ memantine $(10 \mathrm{nM}$ to $50 \mu \mathrm{M}) / \mathrm{L}-\mathrm{NMMA}(10$ to $200 \mu \mathrm{M})$ for $2 \mathrm{~h}$ before the addition of glutamate $(75 \mu \mathrm{M})$. The cell viability was measured at $24 \mathrm{~h}$ after glutamate challenge. B: bis(7)-Cognitin prevents the excitotoxicity in a time-dependent manner. CGNs were exposed to $0.1 \mu \mathrm{M}$ bis(7)-Cognitin/0.1 $\mu \mathrm{M}$ MK-801/5 $\mu \mathrm{M}$ memantine/100 $\mu \mathrm{M}$ L-NMMA 24, 12 and $2 \mathrm{~h}$ before glutamate at $75 \mu \mathrm{M}(-24$, -12 , and $-2 \mathrm{~h}$ ), at the same time as glutamate (0), or 1 and $2 \mathrm{~h}$ after glutamate (1 and $2 \mathrm{~h})$. At $24 \mathrm{~h}$ after the glutamate challenge, the cell viability was measured by 3-(4,5-Dimethylthiazol-2-yl)-2,5-diphenyltetrazolium bromide assay. C: Molecular docking simulation of selective interactions between bis(7)-Cognitin and nNOS, and the dashed lines represent the hydrogen bonds and spiked resides form the hydrophobic interactions with bis(7)-Cognitin. D: The proposed dual mechanism of synergistic neuroprotection against glutamate by bis(7)-Cognitin. When neurons are exposed to glutamate at toxic concentrations, excessive NO mediates downstream signaling pathways of N-methyl-D-aspartate (NMDA) receptors that trigger excitoxicity. Bis(7)-Cognitin concurrently blocks NMDA receptors and inhibits nNOS, thereby synergistically providing substantial neuroprotection (adapted from Li et al., ${ }^{22} 2007$ ). log M = the logarithm of chemical concentrations whose unit is mole per liter (i.e., M).

mate-induced excitotoxicity closely associated with the pathogenesis of acute and chronic neurodegenerative disorders, such as stroke and AD. ${ }^{41}$ Therefore, with two-dimensional differential in-gel electrophoresis, a comparative analysis of mitochondrial protein patterns was carried out to investigate intracellular 
Table 2. Selective Inhibition of NOS by bis(7)-Cognitin In Vitro

\begin{tabular}{lccc}
\hline \multirow{2}{*}{\multicolumn{1}{c}{ Drug }} & \multicolumn{3}{c}{$\mathrm{IC}_{50}(\mu \mathrm{M})$} \\
\cline { 2 - 4 } & $\mathrm{nNOS}$ & $\mathrm{iNOS}$ & $\mathrm{eNOS}$ \\
\hline Bis(7)-Cognitin & 2.9 & 9.3 & $>100$ \\
L-NMMA & 4.1 & 15.0 & 3.8 \\
7-NI & 0.7 & 27.7 & 1.9 \\
MK-801 & & ------ ND $^{*------}$ & \\
Memantine & & ----- ND------
\end{tabular}

In vitro, the activity of the recombinant human nNOS, eNOS, and iNOS and their inhibition by chemicals were measured by the NOS assay kit. $\mathrm{IC}_{50}$ value of each chemical to inhibit nNOS, iNOS and eNOS was obtained from 8 point titration using Sigmaplot 9.0, where each individual point was an average of duplicate determination at the same concentration from three independent experiments. L-NMMA $=\mathrm{N}^{\mathrm{G}}$-monomethyl- L-arginine; NOS $=$ nitric oxide synthase.

*ND means 'not detectable', which indicates that the corresponding chemical did not inhibit the activity of NOS, even at $1 \mathrm{mM}$ (adapted from Li et al., ${ }^{22} 2007$ ).

mechanisms of bis(7)-Cognitin against glutamate-induced excitotoxicity in primary cultured neurons. ${ }^{42} \mathrm{~A}$ total of 29 proteins exhibiting significant difference in their abundance were identified in a glutamate-treated group when compared with the control group. Of these, 22 could be reversed by post-treatment with bis(7)-Cognitin. Most of the differentially expressed proteins are involved in energy metabolism, oxidative stress, and apoptosis. In particular, the changed patterns of four interest proteins (prohibitin, VDAC1, 14-3-3 $\beta$, and Hsp90) were further validated by Western blot analysis. Collectively, these findings suggest that multiple signaling pathways initiated by the changed mitochondrial proteins may not only mediate glutamate-induced excitotoxicity, but also provide po- tentially useful intracellular targets for the neuroprotection of bis(7)-Cognitin (FIG. 9).

\section{Bis(7)-Cognitin attenuates $\beta$-amyloid-induced neuronal apoptosis by regulating $L$-type calcium channels}

The amyloid plaques are generated by deposition of $\mathrm{A} \beta$, which is derived from the amyloid precursor protein through an initial $\beta$-secretase cleavage followed by an intramembraneous cut of $\gamma$-secretase. ${ }^{43}$ Both the fibrillar form and the oligomeric soluble form of $\mathrm{A} \beta$ (SO$\mathrm{A} \beta)^{44,45}$ have been shown to be extremely toxic in several cell models and very important in the pathogenesis of $\mathrm{AD}$. There is increasing evidence that the disruption of $\mathrm{Ca}^{2+}$ homeostasis plays a very important role in the neurotoxicity induced by both the fibrillar $\mathrm{A} \beta$ and SO$\mathrm{A} \beta,{ }^{40,46}$ and the increase of intracellular $\mathrm{Ca}^{2+}\left(\left[\mathrm{Ca}^{2+}\right]_{\mathrm{i}}\right)$ by fibrillar $\mathrm{A} \beta$ has been shown to be mediated via L-type voltage-dependent $\mathrm{Ca}^{2+}$ channels (VDCCs). ${ }^{47,48}$ Given that $\mathrm{A} \beta$ plays an extremely important role in $\mathrm{AD}$ and that $\mathrm{A} \beta$-induced neurotoxicity is supposed to be mediated by overactivation of L-type VDCCs, we investigated the ability of bis(7)-Cognitin to prevent $\mathrm{A} \beta$-induced apoptosis in rat cortical neurons and whether this agent exerted its protection by interfering with L-type VDCCs in primary cultured cortical neurons. ${ }^{38}$

Bis(7)-Cognitin, but not other AChE inhibitors, elicited a marked reduction of $\mathrm{A} \beta$ ( $\mathrm{A} \beta_{25-35}$ fibrils, $\mathrm{A} \beta_{1-42}$ fibrils or SO-A $\beta_{1-42}$ )-induced apoptosis (FIG. 10 ); and both nicotinic and muscarinic receptor antagonists failed to block the effects of bis(7)-Cognitin. Instead, nimodipine, a blocker of L- type VDCCs, attenuated $\mathrm{A} \beta$ neurotoxicity, whereas $\mathrm{N}$-, $\mathrm{P} / \mathrm{Q}$ - or R-type VDCCs blockers, and ionotropic glutamate receptor antagonists could not. With fluorescence $\mathrm{Ca}^{2+}$ imaging assay, it was revealed that (similar to
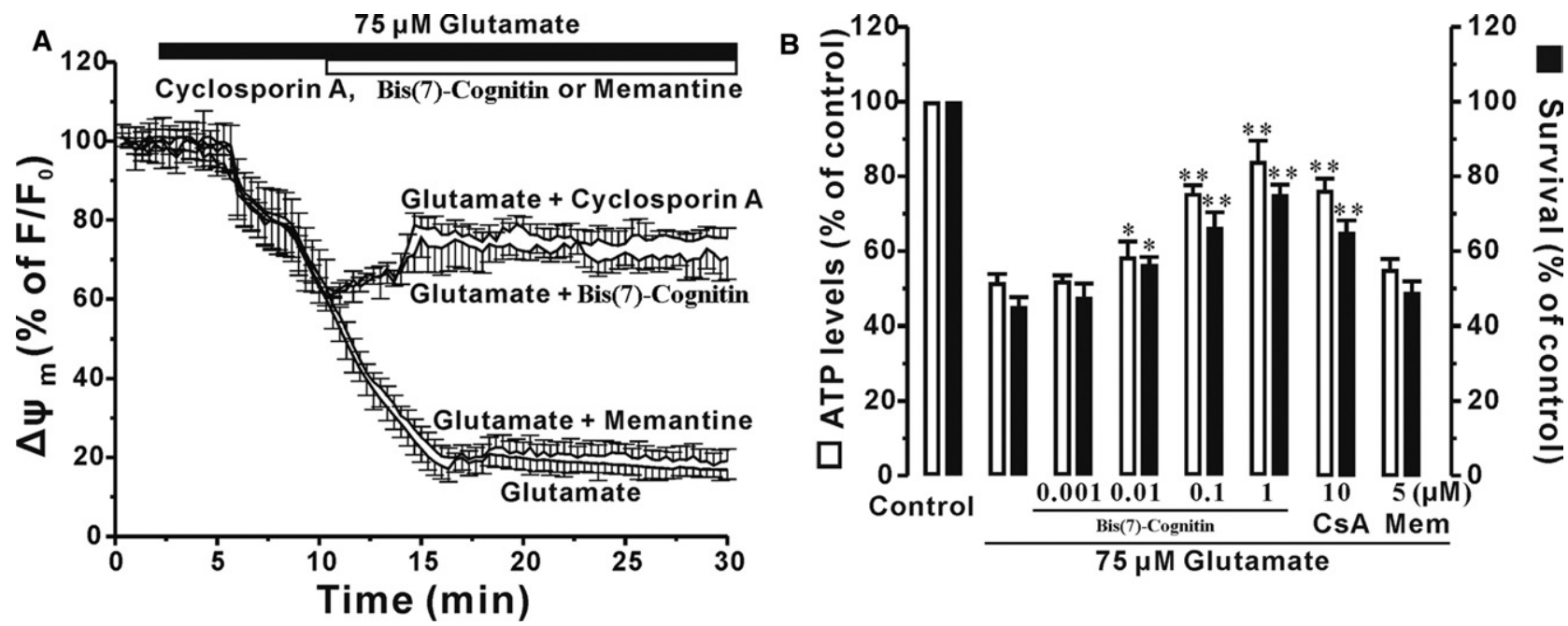

FIG. 8. Bis(7)-Cognitin reverses the impairment of mitochondria caused by glutamate. A: bis(7)-Cognitin and cyclosporine A, but not memantine, blocks the decline of mitochondrial membrane potential $\left(\Delta \Psi_{\mathrm{m}}\right)$ induced by glutamate in CGNs. B: bis(7)-Cognitin and cyclosporine A, but not memantine, reverses the decreases of ATP levels and cell survival rate induced by glutamate in CGNs (adapted from Fu et al., ${ }^{42}$ 2007). 


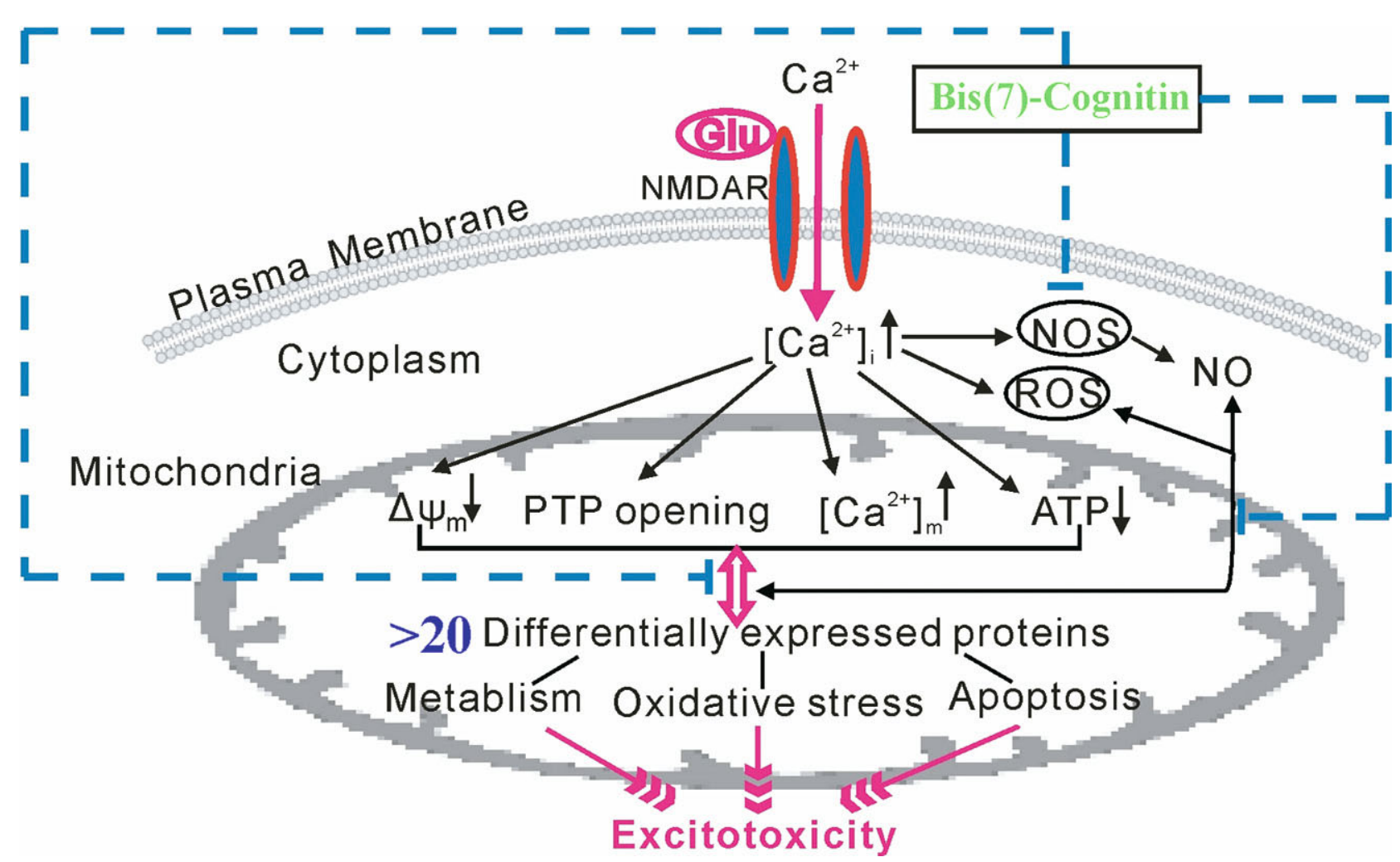

FIG. 9. Proposed potential intracellular mechanisms of the neuroprotection of bis(7)-Cognitin against glutamate-induced excitotoxicity. The overactivation of NMDA receptors by glutamate leads to the overload of intracellular $\mathrm{Ca}^{2+}$, proteomic changes, and finally causes excitotoxicity. On the other hand, post-treatment with bis(7)-Cognitin might prevent glutamate excitotoxicity by maintaining mitochondrial normal function, targeting mitochondrion-associated apoptotic signaling pathways, inhibiting the activity of NOS, and oxidative stress, indicated with the blue dotted flat arrowheads (adapted from Fu et al., ${ }^{22} 2007$ ).

nimodipine) bis(7)-Cognitin reversed $\mathrm{A} \beta$-triggered intracellular $\mathrm{Ca}^{2+}$ increase, which was mainly contributed by the extracellular $\mathrm{Ca}^{2+}$ instead of endoplasmic reticulum and mitochondria $\mathrm{Ca}^{2+}$. Concurrently, using the whole cell patch-clamping technique it was found that bis(7)-Cognitin significantly reduced the augmen- tation of high voltage-activated inward calcium currents induced by $\mathrm{A} \beta$ (FIG. 11). Together, these results suggest that bis(7)-Cognitin attenuates $\mathrm{A} \beta$-induced neuronal apoptosis by regulating L-type VDCCs, which offers a novel modality as to how the agent exerts neuroprotective effects.
A

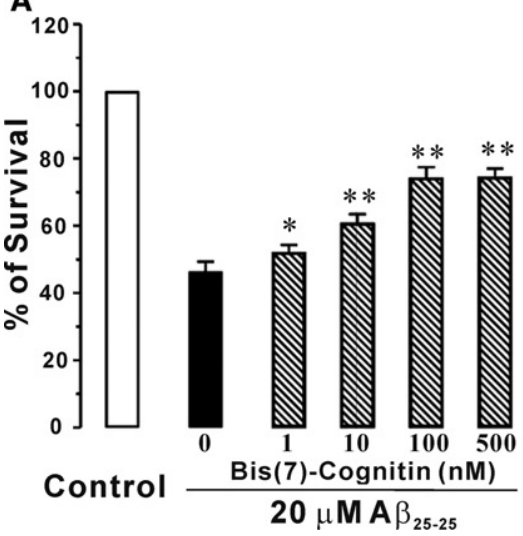

B

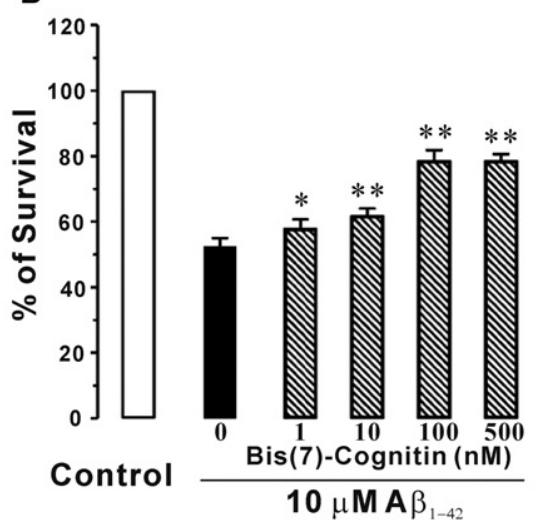

C

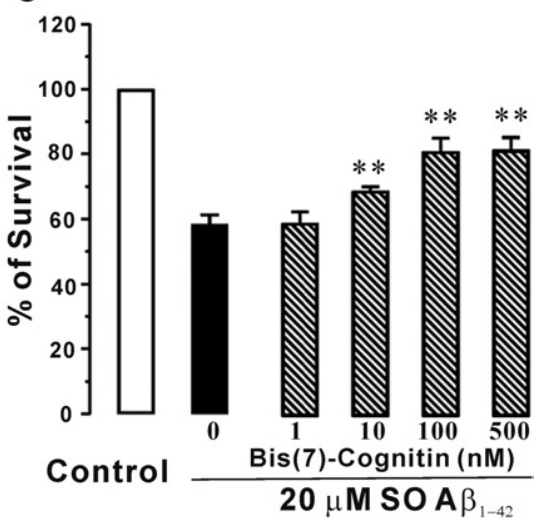

FIG. 10. Bis(7)-Cognitin $A \beta$ attenuates $A \beta$-induced cell death. Cortical neurons were pre-incubated with bis(7)-Cognitin at the different concentrations indicated and were exposed to $20 \mu \mathrm{m} \mathrm{A} \beta_{25-35} / 10 \mu \mathrm{m} \mathrm{A} \beta_{1-43} / 1 \mu \mathrm{m} \mathrm{SO} \mathrm{A} \beta_{1-42} 2 \mathrm{~h}$ later. Forty-eight hours after $A \beta$ challenge, the cell viability was measured by 3-(4,5-Dimethylthiazol-2-yl)-2,5-diphenyltetrazolium bromide assay. All the data, expressed as percentages of control, are the means \pm standard error of the mean of three separate experiments ( $\mathrm{n}=6$ wells for each group). ${ }^{*} P$ $<0.05$; ${ }^{* *} P<0.01$ versus the $A \beta_{25-35}$ group in the graph (A) versus the $A \beta_{1-42}$ group in the graph (B) versus the SO $A \beta_{1-42}$ group in the graph (C) (adapted from Fu et al., ${ }^{2}$ 2006). 
A
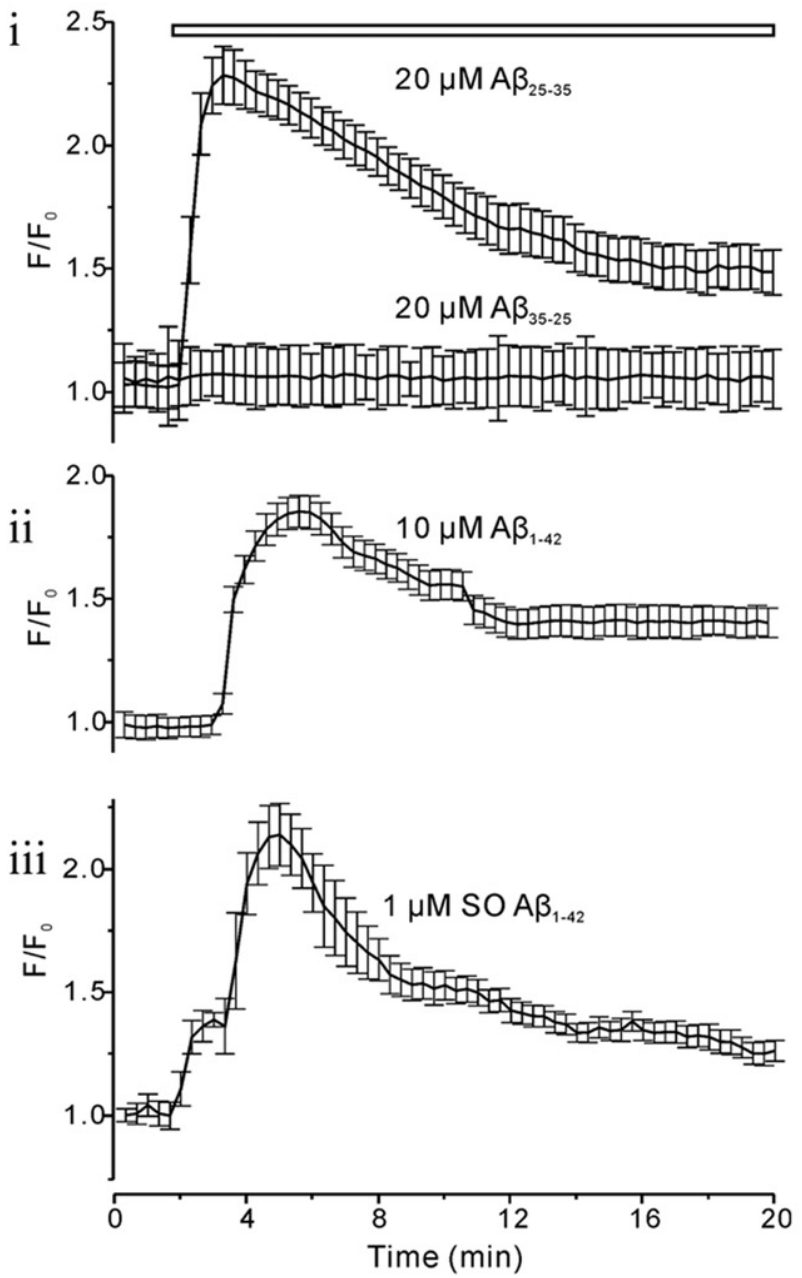

B

i
100 nM Bis(7)-Cognitin

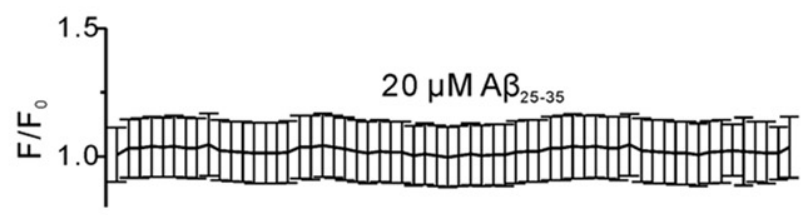

ii

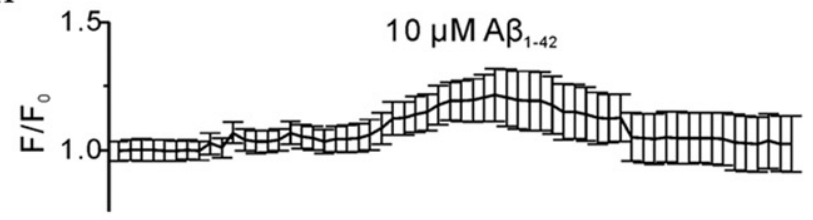

iii

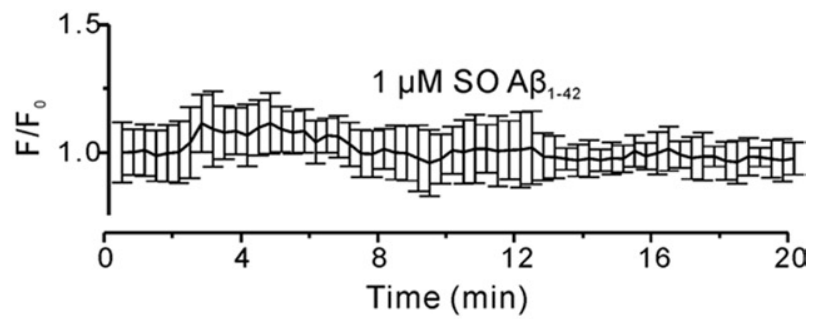

FIG. 11. Bis(7)-Cognitin inhibits the $A \beta$-stimulated $\left[\mathrm{Ca}^{2+}\right]_{\mathrm{i}}$ increase in cortical neurons. A: After scanning resting fluorescence intensity without any treatment for 2 min, cortical neurons were exposed to $A \beta_{25-35} / A \beta_{35-25} / A \beta_{1-42} /$ soluble oligomeric forms of $A \beta$ (SO $\left.A \beta\right)_{1-42}$ and then scanned for $18 \mathrm{~min}$. The blank bar indicates the exposure time of four kinds of $A \beta$. $B$ : Cortical neurons were exposed to $A \beta_{25-35} / A \beta_{1-42} / S O A \beta_{1-42}$ after they were pretreated with bis(7)-Cognitin for $2 \mathrm{~h}$, and then the resting fluorescence intensity was scanned for $2 \mathrm{~min}$. Bis(7)-Cognitin was present during this whole scanning process. The time course curves were based on the relative fluorescence intensity determined by a confocal microscope from cortical neurons exposed to the respective treatments. The data, expressed as $F / F_{0}$, were the means \pm standard error of the mean of three independent experiments (adapted from $F u$ et al., ${ }^{38} 2006$ ).

\section{Bis(7)-Cognitin reverses the inhibition of LTP by SO-A $\beta$ in hippocampal slices}

Although the exact mechanisms of $\mathrm{AD}$ are unclear yet, $\mathrm{A} \beta$ is proposed to play key roles in the pathogenesis of $\mathrm{AD}{ }^{49,50}$ Excessive amyloid precursor protein expression and $\mathrm{A} \beta$ production is a necessary condition for $\mathrm{AD}$. The prevailing amyloid hypothesis for $\mathrm{AD}$ holds that $\mathrm{A} \beta$ causes neurodegeneration by forming neurotoxic fibrillar structure. $^{51}$ Yet many aspects of $\mathrm{AD}$ pathology and symptoms are not well explained by this hypothesis; for example, relatively weak correlations between fibrillar plaque density and severity of dementia are found in $\mathrm{AD}$ brains. ${ }^{45}$ However, increasing evidence shows that the culprit may not be $\mathrm{A} \beta$ itself and $\mathrm{A} \beta$ fibrils, but $\mathrm{SO}-\mathrm{A} \beta$, also referred to as low-n $A \beta$ oligomers, $A \beta$-derived diffusible ligands and protofibrils. ${ }^{52} \mathrm{SO}-\mathrm{A} \beta$ is much more toxic than monomers and fibrils of $\mathrm{A} \beta \mathrm{s}^{53}$ More importantly, SO-A $\beta$ inhibits hippocampal LTP in rats in vivo and in hippocampal slices; and the concentration of $\mathrm{SO}-\mathrm{A} \beta$ also correlates directly with cognitive deficits of $\mathrm{AD}$, indicating that $\mathrm{SO}-\mathrm{A} \beta$ may be the nature of the molecular entity causing dementia. ${ }^{54}$ SO-A $\beta$ might impair memory via synapse loss and kill neurons via neuronal apoptosis by destroying membrane permeabilization, which may initiate downstream signaling pathways, including calcium dyshomeostasis, mitochondrial dysfunction, and microtubule-associated protein proteolysis through synergistic role of calpain and caspase-3.55,56 Therefore, the destructive potential now associated with SO-A $\beta$ suggests that the real breakthroughs in the therapeutics for $\mathrm{AD}$ will emerge through directly targeting the pathological cascade of SO-A $\beta$. Our preliminary data 
A

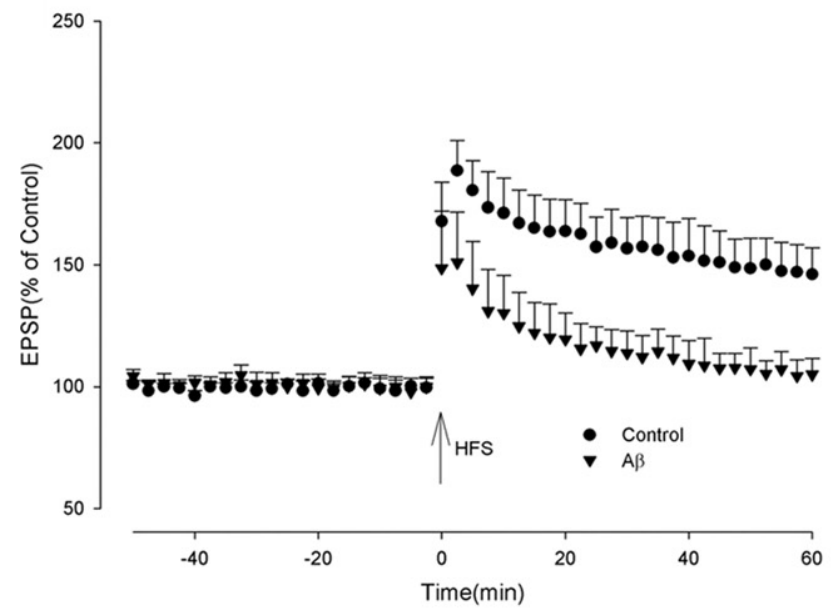

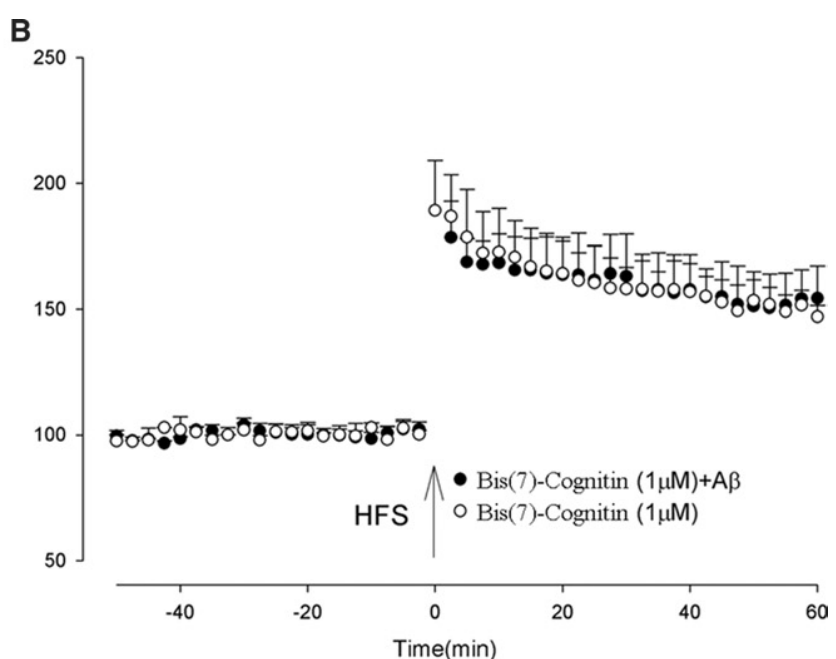

FIG. 12. Bis(7)-Cognitin reverses the inhibition of long-term potentiation (LTP) by soluble oligomeric forms of $A \beta$ (SO-A $\beta$ ). Preparation of rat hippocampal slices and in vitro electrophysiological techniques are carried out as previously described (Wang et al.,53 2004). The control LTP is $149 \pm 8 \%$ at $60 \mathrm{~min}$ after $200 \mathrm{~Hz}$ high-frequency stimulation (HFS), and $0.5 \mathrm{M} \mathrm{SO}-\mathrm{A} \beta$ inhibits it to $105 \pm 6 \%$ (A). Bis(7)-Cognitin at $1 \mu \mathrm{M}$ substantially prevents the inhibition of long-term potentiation (LTP) induced by SO-A $(155 \pm 10 \%)(B)$. EPSP $=$ excitatory postsynaptic potential.

have shown that the natural secreted $\mathrm{SO}-\mathrm{A} \beta$ can potently inhibit LTP-induced by high frequency stimulation (HFS) in rat hippocampus slices. More encouragingly, it has been found that bis(7)-Cognitin can enhance HFSinduced LTP and reverse the inhibition of LTP by $\mathrm{SO}-\mathrm{A} \beta$ in the system just described (FIG. 12).

\section{SUMMARY}

According to the preclinical studies, bis(7)-Cognitin has been shown to have low toxicity and excellent efficacy for improving cognitive deficits in several animal models. In general, bis(7)-Cognitin is a superior $\mathrm{AChE}$ inhibitor with multiple neuroprotective activities in vitro and in vitro. More interestingly, bis(7)-Cognitin prevents glutamate-induced neurotoxicity by moderately blocking glutamate receptor NMDA subtype and selective inhibition of nNOS, and can reverse the glutamate-induced declines of mitochondrial membrane potential, ATP production and neuronal cell death via both NMDA receptor-dependent and -independent ways. Furthermore, this dimer attenuates $\beta$-amyloid-induced neuronal apoptosis by regulating L-type calcium channels, and reverses the inhibition of LTP induced by SO-A $\beta$. Based on these new findings, we conjecture that bis(7)-Cognitin appears to block the pathological cascades of $\mathrm{AD}$ at multiple sites concurrently, which offers a new and clinically significant modality as to how this dimer exerts substantial neuroprotective activities. More importantly, the synergism between anti-AChE, -NMDAR/NOS and $-\mathrm{A} \beta$ cascade might serve as one of the most effective therapeutic strategies to prevent and slow down the neurodegeneration, in addition to improving the cognitive functions for AD. Collectively, these findings related to promising
anti-Alzheimer candidate bis(7)-Cognitin not only provide a new direction to rationally design more effective drugs with multiple targets for both the prevention and treatment of $\mathrm{AD}$ or even other neurodegenerative diseases, but also offer a new insight into the molecular basis of effective therapeutic strategies for these diseases.

Acknowledgments: This research is supported by grants from the Research Grants Council of Hong Kong (PolyU6441/ 06M, 6608/07M; N_PolyU618/07), Hong Kong PolyU (GYX96, G-U439), the Ministry of Science and Technology (MOST) of China (2008CB517411), and the Shenzhen Shuangbai Scheme 08.

\section{REFERENCES}

1. Heppner FL, Gandy S, McLaurin J. Current concepts and future prospects for Alzheimer disease vaccines. Alzheimer Dis Assoc Disord 2004;18:38-43.

2. Marx J. New "Alzheimer's mouse" produced. Science (Washington D.C.) 1996;273:50-53.

3. Kamer AR, Dasanayake AP, Craig RG, Glodzik-Sobanska L, Bry M, de Leon MJ. Alzheimer's disease and peripheral infections: the possible contribution from periodontal infections, model and hypothesis. J Alzheimers Dis 2008;13:437-449.

4. Van Marum RJ. Current and future therapy in Alzheimer's disease. Fundam Clin Pharmacol 2008;22(3):265-274.

5. Kihara T, Shimohama S. Alzheimer's disease and acetylcholine receptors. Acta Neurobiol Exp 2004;64:99-105.

6. Francotte P, Graindorge E, Boverie S, de Tullio P, Pirotte B. New trends in the design of drugs against Alzheimer's disease. Curr Med Chem 2004;11:1757-1778

7. Liu JS, Zhu YL, Yu CM, Han YY, Yu FW. The structure of huperzine $\mathrm{A}$ and $\mathrm{B}$, two new alkaloids exibiting marked anticholinesterase activity. Can J Chem 1986;64:837-839.

8. Tang XC, Han YF, Chen XP, Zhu XD. Effects of huperzine A on learning and retrieval process of discrimination performance in rats. Acta Pharmacol Sin 1986;7:501-511.

9. Tang XC, Xiong ZQ, Qian BC, Zhou ZF, Zhang CC. Cognitive improvement by oral huperzine A: a novel acetylcholinesterase 
inhibitor. In "Alzheimer Therapy: Therapeutic Strategies" (Eds: Giacobini E and Becker R), Birkhäuser, Boston, 1994:113-119.

10. Han YF, Tang XC. Preclinical and clinical progress with huperzine A: a novel acetylcholinesterase inhibitor. In "Alzheimer Therapy: Therapeutic Strategies" (Eds: Giacobini E and Becker R), Birkhäuser, Boston, 1996:245-250.

11. Tang XC, Han YF. Pharmacological profile of huperzine A, a novel acetylcholinesterase inhibitor from Chinese herb. CNS Drug Reviews 1999;5(3):281-300.

12. Xu SS, Gao ZZ, Weng Z, Du ZM, Xu W. Efficacy of tablet huperzine-A on memory, cognition, and behavior in Alzheimer's disease. Acta Pharmacologica Sinica 1995;16:391-395.

13. Xu SS, Gao ZZ, Weng Z, Du ZM, Xu W. Efficacy of tablet huperzine-A on memory, cognition, and behavior in Alzheimer's disease. Acta Pharmacologica Sinica 1999;20:489-490.

14. Sonkusare SK, Kaul CL, Ramarao P. Dementia of Alzheimer's disease and other neurodegenerative disorders-memantine, a new hope. Pharmacol Res 2005;51:1-17.

15. Van Marum RJ. Current and future therapy in Alzheimer's disease. Fundam Clin Pharmacol 2008;22(3):265-274.

16. Youdim MB, Buccafusco JJ. CNS Targets for multi-functional drugs in the treatment of Alzheimer's and Parkinson's diseases. J Neural Transm 2005;112:519-537.

17. Zhang HY. One-compound-multiple-targets strategy to combat Alzheimer's disease. FEBS Lett 2005;579:5260-5264.

18. Frantz S. Drug discovery: playing dirty. Nature 2005;437:942943.

19. Van der Schyf CJ, Mandel S, Geldenhuys WJ, et al. Novel multifunctional anti-Alzheimer drugs with various CNS neurotransmitter targets and neuroprotective moieties. Curr Alzheimer Res 2007;4(5):522-536.

20. Voisin T, Reynish E, Portet F, Feldman H, Vellas B. What are the treatment options for patients with severe Alzheimer's disease? CNS Drugs 2004; 18:575-583.

21. Carlier PR, Du DM, Han YF, Liu J, Pang YP. Potent, easily aynthesized Huperzine A-tacrine hybrid acetylcholinesterase inhibitors. Bioorg Med Chem Lett 1999;9:2335-2338.

22. Li WM, Xue J, Niu C, et al. Synergistic neuroprotection by bis(7)tacrine via concurrent blockade of N-methyl-D-aspartate receptors and neuronal nitric-oxide synthase. Mol Pharmacol 2007;71:12581267.

23. Sussman JL, Harel M, Frolow F, et al. Atomic structure of acetylcholinesterase from Torpedo californica: a prototypic acetylcholine-binding protein. Science 1991;253:872-879.

24. Amitai G, Taylor P. Cholinesterases: structure, function, mechanism, genetics and cell biology. In: American Chemical Society, Washington, DC. 1991, 285

25. Weise C, Kreienkamp HJ, Raba R, Pedak A, Aaviksaar A, Hucho F. Anionic subsites of the acetylcholinesterase from Torpedo californica: affinity labelling with the cationic reagent $\mathrm{N}, \mathrm{N}$-dimethyl2-phenyl-aziridinium. EMBO J 1990;9:3885-3888.

26. Taylor P, Lappi S. Interaction of fluorescence probes with acetylcholinesterase: the site and specificity of propidium binding. Biochem 1975;14:1989-1997.

27. Rosenberry TL, Neumann E. Interaction of ligands with AChE. Use of temperature-jump relaxation kinetics in the binding of specific fluorescent ligands. Biochemistry 1977;16:3870-3878.

28. Pang YP, Quiram P, Jelacic T, Hong F, Brimijoin S. Highly potent, selective, and low cost bis-tetrahydroaminacrine inhibitors of acetylcholinesterase. J Biol Chem 1996;271:23646-23649.

29. Ellman GL, Courtney KD, Andre V Jr, Featherstone RM. A new and rapid colorimetric determination of acetylcholinesterase activity. Biochem Pharmacol 1961;7:88-95.

30. Yu H, Li WM, Kan KK, et al. The physicochemical properties and the in vivo AChE inhibition of two potential anti-Alzheimer agents, bis(12)-hupyridone and bis(7)-tacrine. J Pharm Biomed Anal 2008;46(1):75-81.

31. Wang H, Carlier PR, Ho WL, Lee NTK, Pang YP, Han YF. Attenuation of scopolamine-induced deficits in navigational memory performance in rats by bis(7)-tacrine, a novel dimeric AChE inhibitor. Acta Pharmacol Sinica 1999;20:211-217.

32. Liu J, Ho WL, Lee NT, Carlier PR, Pang YP, Han YF. Bis(7)tacrine, a novel acetylcholinesterase inhibitor, reverses AF64A- induced deficits in navigational memory in rats. Neurosci Lett 2000;282:165-168.

33. Yuan J, Yankner BA. Apoptosis in the nervous system. Nature 2000;407:802-809.

34. Bachis A, Colangelo AM, Vicini S, et al. Interleukin-10 prevents glutamate-mediated cerebellar granule cell death by blocking caspase-3-like activity. J Neurosci 2001;21:3104-3112.

35. Wu DC, Xiao XQ, Ng AK, et al. Protection against ischemic injury in primary cultured mouse astrocytes by bis(7)-tacrine, a novel acetylcholinesterase inhibitor. Neurosci Lett 2000;288:95-98.

36. Xiao XQ, Lee NT, Carlier PR, Pang YP, Han YF. Bis(7)-tacrine, a promising anti-Alzheimer's agent, reduces hydrogen peroxideinduced injury in rat pheochromocytoma cells:comparison with tacrine. Neurosci Lett 2000;290:197-200.

37. Li WM, Pi RB, Chan HHN, et al. Novel dimeric acetylcholinesterase inhibitor bis7-tacrine, but not donepezil, prevents glutamateinduced neuronal apoptosis by blocking N-methyl-D-aspartate receptors. J Biol Chem 2005;280:18179-18188.

38. Fu H, Li W, Lao Y, et al. Bis(7)-tacrine attenuates beta amyloidinduced neuronal apoptosis by regulating L-type calcium channels. J Neurochem 2006;98(5):1400-1410.

39. Zhao Y, Li W, Chow PC, et al. Bis(7)-tacrine, a promising antiAlzheimer's dimer, affords dose- and time-dependent neuroprotection against transient focal cerebral ischemia. Neurosci Lett 2008; 439(2):160-164.

40. Mattson MP. Pathways towards and away from Alzheimer's disease. Nature 2004;430:631-639.

41. Nicholls DG. Mitochondrial dysfunction and glutamate excitotoxicity studied in primary neuronal cultures. Curr Mol Med 2004;4: 149-177.

42. Fu H, Li W, Liu Y, et al. Mitochondrial proteomic analysis and characterization of the intracellular mechanisms of bis(7)-tacrine in protecting against glutamate-induced excitotoxicity in primary cultured neurons. J Proteome Res 2007;6(7):2435-2446.

43. Selkoe DJ. Alzheimer's disease:genes, proteins, and therapy. Physiol Rev 2001;81:741-766.

44. Dahlgren KN, Manelli AM, Stine WB Jr, et al. Oligomeric and fibrillar species of amyloid-beta peptides differentially affect neuronal viability. J Biol Chem 2002;277:32046-32053.

45. Kim HJ, Chae SC, Lee DK, et al. Selective neuronal degeneration induced by soluble oligomeric amyloid beta protein. FASEB J 2003; 17:118-120.

46. Demuro A, Mina E, Kayed R, Milton SC, Parker I, Glabe CG. Calcium dysregulation and membrane disruption as a ubiquitous neurotoxic mechanism of soluble amyloid oligomers. J Biol Chem 2005;280:17294-17300.

47. Davidson RM, Shajenko L, Donta TS. Amyloid beta-peptide (A beta $\mathrm{P}$ ) potentiates a nimodipine-sensitive L-type barium conductance in N1E-115 neuroblastoma cells. Brain Res 1994;643:324327.

48. Ueda K, Shinohara S, Yagami T, Asakura K, Kawasaki K. Amyloid beta protein potentiates $\mathrm{Ca}^{2+}$ influx through L-type voltagesensitive $\mathrm{Ca}^{2+}$ channels:a possible involvement of free radicals. J Neurochem 1997;68:265-271.

49. Fu H, Li W, Luo J, et al. Promising anti-Alzheimer's dimer bis(7)tacrine reduces beta-amyloid generation by directly inhibiting BACE-1 activity. Biochem Biophys Res Commun 2008;366(3): 631-636.

50. Nalbantoglu J, Tirado-Santiago G, Lahsaini A, et al. Impaired learning and LTP in mice expressing the carboxy terminus of the Alzheimer amyloid precursor protein. Nature 1997;387: 500-505.

51. Peng Y, Jiang L, Lee DY, Schachter SC, Ma Z, Lemere CA. Effects of huperzine A on amyloid precursor protein processing and beta-amyloid generation in human embryonic kidney 293 APP Swedish mutant cells. J Neurosci Res 2006;84:903-911.

52. Hardy J, Selkoe DJ. The amyloid hypothesis of Alzheimer's disease: progress and problems on the road to therapeutics. Science 2002;297:353-356.

53. Wang QW, Walsh DM, Rowan MJ, Selkoe DJ, Anwyl R. Block of long-term potentiation by naturally secreted and synthetic amyloid peptide in hippocampal slices is mediated via activa- 
tion of the kinases c-Jun-terminal kinase, cyclin-dependent kinase5, and p38 mitogen-activated protein kinase as well as metabotropic glutamate receptor type5. J Neurosci 2004;24: $3370-3378$.

54. Cleary JP, Walsh DM, Hofmeister JJ, et al. Natural oligomers of the amyloid beta protein specifically disrupt cognitive function. Nat Neurosci 2005;8:79-84.
55. Glabe CG, Kayed R. Common structure and toxic function of amyloid oligomers implies a common mechanism of pathogenesis. Neurology 2006;66:S74-78.

56. Malaplate-Armand C, Florent-Bechard S, Youssef I, et al. Soluble oligomers of amyloid-beta peptide induce neuronal apoptosis by activating a cPLA2-dependent sphingomyelinase-ceramide pathway. Neurobiol Dis 2006;23:178-189. 